\title{
Economic impact of the clinical pharmacist interventions in the pediatric intensive care unit
}

\author{
Bruna de Melo Menezes ${ }^{1,2}$ (D), Francieli Zanella-Lazaretto ${ }^{1}$ (D), Lucélia Hernandes-Lima ${ }^{1}$ (D), \\ Karin Hepp-Schwambach ${ }^{2}$ (D) , Carine Raquel Blatt ${ }^{2 \star}$ (D) \\ ${ }^{1}$ Irmandade da Santa Casa de Misericórdia de Porto Alegre, Porto Alegre, RS, Brasil \\ Universidade Federal de Ciências da Saúde de Porto Alegre (UFCSPA), Porto Alegre, RS, Brasil \\ *Corresponding author: carineblatt@ufcspa.edu.br
}

\begin{abstract}
Clinical pharmacists in intensive care units are involved in patient safety, technical guidance and cost saving with rational use of medicines. This study aimed to estimate the cost saving of clinical pharmacist interventions in pediatric intensive care units (PICU). This was a retrospective, observational study. Savings were measured for three months based on (1) Clinical pharmacist interventions from prescription analysis, (2) Individualized doses of four antibiotics, (3) Comparison of drugs dispensing systems before and after the decentralization of pharmacy services. The main outcome is costs saving with strategic planning of medication use based on local reality. A number of 73 clinical pharmacist interventions were made, from which 13 allowed the calculation of economic impact, saving US\$ 633.38/year. Cost saving from individualized doses of four antibiotics was US $\$ 8,754.46 /$ year. The decentralization of pharmacy services saved US $\$ 28,770.52 /$ year. The evaluated interventions were successful. Clinical pharmacist interventions, individualized antimicrobials doses and decentralization of pharmacy services reduce costs in the hospital..
\end{abstract}

Keywords: Clinical Pharmacist. Cost Saving. Intensive Care Units. Pediatric.

\section{How to cite}

Menezes BM, Zanella-Lazaretto F, Hernandes-Lima L, Hepp-Schwambach K, Blatt CR. Economic impact of the clinical pharmacist interventions in the pediatric intensive care unit. Rev Ciênc Farm Básica Apl. 2020;41:e670. https://doi.org/10.4322/2179-443X.0670

\section{INTRODUCTION}

In Brazil, the presence of clinical pharmacists in Intensive Care Units (ICU) is recent (Brasil, 2019). These professionals are crucial in daily ICU patient care by assisting physicians and other health care providers with pharmacotherapy decision making and monitoring to improve medication safety (Preslaski et al., 2013).

Clinical pharmacists in ICU are involved in patient safety, technical guidance and cost saving with rational use of medicines. However, ensuring comprehensive and quality access to health care is complex, often filled with challenges, such as the absence of guidelines, professional turnover and new technology availability (Fideles et al., 2015). Clinical pharmacist interventions can be described as a planned documented action that aims to 
solve or prevent problems related to pharmacotherapy (Ivama et al., 2002). Many studies have evaluated the impact of pharmacist interventions in hospitals and showed positive economic outcome (Muñoz-Pichuante \& Villa-Zapata, 2020; Gallagher et al., 2014; Klopotowska et al., 2010; Baldinger et al., 1997). These studies have already demonstrated this effect in adult ICU, however, pediatric intensive care units still require more studies (Larochelle et al., 2012).

Pediatric patients present significantly different physiological characteristics from adults e.g., pharmacokinetics and pharmacodynamics -, thus being more susceptible to medication errors and their consequences (Kaestli et al., 2014). These particularities are also present in Pediatric Intensive Care Units (PICU). Professionals working in them need to calculate drug dosage based on weight, and the maximum concentration of some intravenous solutions are examples of how this population requires specific care with drug prescription, dispensing, preparation and administration (Potts et al., 2004).

A systematic review of non-randomized controlled studies evaluated the effect of pharmacist services on medication errors rates in ICU versus no intervention. Four studies were included in the meta-analysis and results suggest that pharmacist intervention had no significant contribution in reducing errors, although it may significantly reduce preventable adverse drug events and prescribing errors (Wang et al., 2015).

Regarding economic impact, the best intervention depends on the characteristics of each hospital unit. Thus, it is essential to know medication consumption, current guidelines, and pharmacy services, in order to establish points that could save the most money, which can be targets of these actions.

Besides the benefits of clinical pharmacist intervention in patient safety in ICU, this study aims to estimate the cost saving of clinical pharmacist interventions and pharmacy services in PICU.

\section{METHODS}

This is a descriptive study focused on costs analysis and developed by a resident pharmacist of a multidisciplinary team of critically ill patients, carried out at the Pediatric Intensive Care Unit (PICU) of the "Hospital da Criança Santo Antônio" (HCSA) in Irmandade Santa Casa de Misericórdia dePorto Alegre (ISCMPA). This PICU is assisted by a multidisciplinary team of professionals and residents (Medicine, Nursing, Physical Therapy, Speech-Language Therapy, Psychology, Nutrition and Pharmacy). The PICU has 30 beds and is a reference in several pediatric specialties - mainly in congenital heart diseases -, and attends to patients from different Brazilian states.

Cost saving was estimated for one year and identified by (1) pharmacist interventions resulting from the analysis of prescriptions, (2) individualized doses of four antibiotics, (3) comparison of the dispensing system before and after pharmacy decentralization. All costs were converted to US dollars (July 01, 2016; US $\$ 1=R \$ 3.2292$ ). Only the cost of drugs was measured.

\section{Pharmacist interventions from prescriptions analysis}

Pharmacist interventions were recorded in July 2015. The most frequent interventions were classified as prescription adjustment, drug dose adjustment, drug administration routes management, drug reconstitution and dilution, replacement for standard drug, drug suspension, drug exchange, administration schedule exchange and others. These interventions started from prescription analysis or request of a service team. The accepted pharmacist interventions were evaluated and the costs were estimated. The costs of drugs 
involved in the intervention were estimated using the average amount paid by the institution in the last three months.

In the case of replacement for standard drug, the cost was calculated considering the number of days used, frequency of use per day, and average prices of drugs. Cost saving is represented by the difference between drugs A and B. For drug suspension, cost was calculated by the number of days used, frequency of use per day, and average drug prices. For dose or administration route adjustment, the drug cost was calculated considering the need to prevent loss due to medication incompatibilities, according to current literature. Loss of medication was considered if the wrong dose or route of administration prescribed before the intervention was used.

\section{Individualized doses of four antibiotics}

The profile of drug consumption in the PICU from January 1st to December 31st, 2015 was organized by Pareto's analysis. The medicine prices were available in the hospital procurement department. The drug selection criteria were a) belonging to Curve A in Pareto's analysis; b) small doses prescribed for pediatric patients; c) reduced stability.

Strategies were discussed with the medical and nursing leader to optimize or implement the use of these drugs. From that, four antimicrobials were chosen: cefepime $1 \mathrm{~g}$, meropenem $500 \mathrm{mg}$, tigecycline $50 \mathrm{mg}$ and vancomycin $500 \mathrm{mg}$. All of them are injectable.

The total dose of prescribed antibiotics, the number of ampoules needed to complete the dosage and the effective quantity dispensed were identified by a report of the institution information technology service. The number of ampoules needed to complete the dose was calculated by the total prescribed dosage and the volume (mg) of the bottle. Cost saving was calculated by the difference between dispensed and necessary dose and estimated over a period of 1 year.

\section{Comparison of drug distribution systems before and after pharmacy decentralization}

From December 15th, 2015 to July 13th, 2016, the process of pharmacy decentralization occurred. The institution consists of seven hospitals with different specialties and had a single pharmacy that delivered drugs to patients in hospital units. After this process, the institution had six pharmacies. All decentralized units retained the same numbers of pharmacists. Cost savings were accounted for by reducing duplicate drugs, resulting from better control of drug dispensing.

A computerized report informing the quantity of drugs that were dispensed in each period was created. Cost saving was calculated comparing the post-decentralization period with the same period in the previous year. The HCSA Pharmacy was implemented in March 2016; therefore, the monthly values compared were those of PICU prescriptions and their costs from April to September of 2015 and 2016.

This study was approved by the Research Ethics Committee of ISCMPA, Rio Grande do Sul, Brazil, in June 2016, under the protocol number CAAE 57409316.7.0000.5683.

\section{RESULTS}

The pharmacist interventions in the PICU were described and classified according to Table 1. Of $173 \mathrm{CPIs}, 97.7 \%$ were accepted. Most interventions were related to drug reconstitution and dilution. In only $13 \mathrm{PI}$ it was possible to quantify cost saving. 
Table 1. Number and type of clinical pharmacist interventions in the pediatric intensive care unit from July to December 2015.

\begin{tabular}{|c|c|c|c|c|c|c|c|}
\hline Intervention & July & August & September & October & November & December & $\begin{array}{c}\text { Number } \\
\text { and } \\
\text { frequency } \\
(\%)\end{array}$ \\
\hline $\begin{array}{l}\text { Prescription } \\
\text { adjustment }\end{array}$ & 0 & 0 & 0 & 0 & 1 & 0 & $1(0.58 \%)$ \\
\hline $\begin{array}{l}\text { Drug doses } \\
\text { adjustment }\end{array}$ & 0 & 0 & 1 & 0 & 3 & 0 & $4(2.32 \%)$ \\
\hline $\begin{array}{l}\text { Drug } \\
\text { administration } \\
\text { routes } \\
\text { management }\end{array}$ & 0 & 1 & 0 & 3 & 2 & 1 & 7 (4.05\%) \\
\hline $\begin{array}{l}\text { Drug } \\
\text { reconstitution } \\
\text { and dilution }\end{array}$ & 13 & 25 & 24 & 18 & 33 & 33 & $\begin{array}{c}146 \\
(84.40 \%)\end{array}$ \\
\hline $\begin{array}{l}\text { Replacement to } \\
\text { standard drug }\end{array}$ & 1 & 0 & 1 & 0 & 0 & 0 & $2(1.15 \%)$ \\
\hline $\begin{array}{l}\text { Drug } \\
\text { suspension }\end{array}$ & 1 & 1 & 1 & 1 & 1 & 1 & $6(3.47 \%)$ \\
\hline Drug exchange & 2 & 0 & 0 & 0 & 0 & 0 & $2(1.15 \%)$ \\
\hline $\begin{array}{l}\text { Administration } \\
\text { schedule } \\
\text { exchange }\end{array}$ & 0 & 0 & 0 & 1 & 0 & 1 & $2(1.15 \%)$ \\
\hline Others & 1 & 0 & 1 & 0 & 1 & 0 & $3(1.73 \%)$ \\
\hline Total & 17 & 28 & 28 & 22 & 43 & 35 & $\begin{array}{c}173 \\
(100.0 \%)\end{array}$ \\
\hline
\end{tabular}

The accepted interventions and cost saving are presented in Table 2. The intervention with the greatest impact was the management of medication administration (alteplase and heparin), which showed incompatibility of administration in $Y$, presenting turbidity and formation of visible crystals 24 hours after starting administration.

Table 2. Type, number and cost saving of accepted clinical pharmacist interventions in the pediatric intensive care unit from July to December 2015.

\begin{tabular}{lcc}
\hline \multicolumn{1}{c}{ Type } & Number & Cost saving (US\$) \\
\hline Drug administration routes management & 1 & 263.18 \\
Replacement by standard drug & 2 & 21.63 \\
Others & 2 & 11.13 \\
Drug suspension & 4 & 9.10 \\
Drug exchange & 2 & 5.25 \\
Prescription adjustment & 1 & 3.99 \\
Drug dosage adjustment & 1 & 2.42 \\
Total & $\mathbf{1 3}$ & $\mathbf{3 1 6 . 6 9}$ \\
\hline
\end{tabular}

The pediatric ICU has 30 beds, 18 public and 12 private, with $80.09 \%$ average monthly occupancy, and 8.9 days as the average stay. The costs of a hospitalization day can vary according to the complexity of the care provided to each patient.

Table 3 shows the consumption and costs of four antimicrobials with individualized doses (cefepime, meropenem, tigecycline and vancomycin). Sharing antibiotic doses can save US\$ 8,754.46 per year. 
Table 3. Consumption and annual estimate cost saving of antimicrobials with individualized doses in pediatric intensive care unit.

\begin{tabular}{lccccc}
\hline \multicolumn{1}{c}{ Medicines } & $\begin{array}{c}\text { Number of } \\
\text { bottles } \\
\text { necessary for a } \\
\text { total dose }\end{array}$ & $\begin{array}{c}\text { Bottle } \\
\text { Consumption }\end{array}$ & $\begin{array}{c}\text { Unitary } \\
\text { costs } \\
\text { (US\$) }\end{array}$ & $\begin{array}{c}\text { Difference } \\
\text { between } \\
\text { necessary and } \\
\text { consumed (US\$) }\end{array}$ & $\begin{array}{c}\text { Cost } \\
\text { saving } \\
\text { (US\$) }\end{array}$ \\
\hline Cefepime 1g & $4,506.38$ & $5,583.00$ & 2.63 & -989.62 & $2,604.91$ \\
Meropenem 500 mg & $5,158.92$ & $5,909.00$ & 1.54 & -937.08 & $1,448.05$ \\
Tigecycline 50 mg & 2.60 & 19.00 & 45.31 & -15.40 & 697.80 \\
Vancomycin 500 mg & $4,482.57$ & $6,655.00$ & 1.76 & $-2,272.19$ & $4,003.70$ \\
Total & & & & & $\mathbf{8 , 7 5 4 . 4 6}$ \\
\hline
\end{tabular}

Comparing the post-decentralization period with the same period in the previous year, the PICU showed US $\$ 28,772.52$ per year in cost saving by avoiding duplicate drug dispensing, see Table 4.

Table 4. Numbers and costs from duplicated drug dispensing considering two periods: 2015 (Central Pharmacy) and 2016 (Pharmacy decentralization) in pediatric intensive care unit.

\begin{tabular}{|c|c|c|c|c|c|c|}
\hline \multirow[t]{2}{*}{ Period } & \multicolumn{2}{|c|}{$\begin{array}{c}\text { Number of } \\
\text { duplicate drug } \\
\text { dispensing }\end{array}$} & \multicolumn{2}{|c|}{ Costs (U\$) } & \multirow{2}{*}{$\begin{array}{c}\text { Costs } \\
\text { difference } \\
\text { (U\$) }\end{array}$} & \multirow[t]{2}{*}{$\begin{array}{c}\text { Costs } \\
\text { difference } \\
(\%)\end{array}$} \\
\hline & 2015 & 2016 & 2015 & 2016 & & \\
\hline April & 368 & 267 & $7,047.39$ & $1,149.07$ & $5,898.32$ & $83.70 \%$ \\
\hline May & 289 & 501 & 860.43 & $1,673.31$ & -812.88 & $-94.00 \%$ \\
\hline June & 239 & 218 & $1,962.31$ & 967.81 & 994.50 & $50.65 \%$ \\
\hline July & 592 & 306 & $2,716.16$ & 491.11 & $2,225.05$ & $81.92 \%$ \\
\hline August & 790 & 92 & $3,642.25$ & 329.30 & $3,312.95$ & $90.96 \%$ \\
\hline September & 1494 & 62 & $3,183.57$ & 415.25 & $2,768.31$ & $86.96 \%$ \\
\hline Average & 628 & 241 & $3,235.35$ & 837.64 & 2,397.71 & $50.03 \%$ \\
\hline Total & 3772 & 1446 & $19,412.11$ & $5,025.85$ & $14,386.26$ & $74.11 \%$ \\
\hline
\end{tabular}

According to our three interventions scenarios, we estimated a US\$38,160.36/year cost saving (Table 5).

Table 5. Costs saving estimated for one year (US\$)

\begin{tabular}{lcc}
\hline Intervention & $\begin{array}{c}\text { Estimated } \\
\text { (US\$) }\end{array}$ & $\begin{array}{c}\text { Extrapolation for 1 } \\
\text { year (US\$) }\end{array}$ \\
\hline Pharmacist Prescription Analysis & 316.69 in 6 months & 633.38 \\
Individualized doses of four antibiotics & $8,754.46$ in 1 year & $8,754.46$ \\
Comparison of the dispensing system before and & $14,386.26$ in 6 months & $28,772.52$ \\
after pharmacy decentralization. & & $38,160.36$ \\
Total & & \\
\hline
\end{tabular}

\section{DISCUSSION}

According to our results, all actions evaluated generated US $\$ 38,160.36 /$ year in cost saving. Individual pharmaceutical interventions in ICU environments have already been reported to reduce costs by the literature (Muñoz-Pichuante \& Villa-Zapata, 2020; Kjeldsen et al., 2011; Schumock et al., 2003; Baldinger et al., 1997). The clinical activities performed by pharmacists in ICU were guided by patient care, aiming to solve or prevent problems related to drug therapy, focusing on patient safety (Aghili \& Kasturirangan, 2020; Malfará et al., 2018; Tripathi et al., 2015; Klopotowska et al., 2010). In practice, not all proposed pharmacist interventions will reduce costs, only optimizing patient care, such as administration schedule 
exchange, as seen in our results. These interventions can be directly measured, but we must consider safety and therapeutical problems that could result in new health problems, new procedures, longer hospitalization or readmission.

Among all interventions evaluated in the present study, 97.7\% were accepted by the team, as in the study conducted at a PICU of a Medical School Hospital in São Paulo, Brazil (Malfará et al., 2018). This study demonstrated that, of 1,586 prescriptions evaluated by the pharmacist, pharmacotherapy-related problems appeared in 12.4\% of them. There were 197 interventions with $\mathrm{R} \$ 15,118.73$ (US\$ 4,828.00) in cost saving (Malfará et al., 2018). Both studies demonstrated a similar pharmacist intervention profile and cost saving as a result.

The pharmacist practice at PICU for longer periods improves their knowledge about drug profiles, and consequently, increases the possibilities of identifying strategies for rational use of medicines when considering patient safety and cost saving (Preslaski et al., 2013). Antimicrobials are also frequently the subject of pharmacoeconomic studies (Pinto et al., 2016; De Giorgi et al., 2010).

A systematic review evaluated the efficacy of interventions in reducing medication errors in intensive care and found four intervention types that reduced medication errors: changes in work schedules, modes of education, medication reconciliation and protocols, and guidelines. The review showed lack of conclusive data to support the use of interventions to reduce medication error rates (Manias et al., 2012).

The present study investigated aspects related to medication costs in intensive care unit of pediatric patients. Another study identified 31 types of errors related to the use of injectable drugs in pediatric and neonatal populations and performed a pharmacoeconomic evaluation, suggesting ready-to-use syringes and the involvement of pharmacists as the best alternative for safe care practices (De Giorgi et al., 2010).

The third scenario investigated in our study demonstrated the economic impact of decentralized pharmacy service. The control of drug dispensing is one of the first steps in patient care and safety (Serafim et al., 2010). After this application, we observed a decrease in the number of double dispensing of prescriptions. Aspects such as greater contact between pharmacist, pharmacy employees and ICU team are key in improving communication and, consequently, drug logistics.

The analysis of the economic benefits caused by the decentralization of the pharmacy service through the evaluation of dual dispensation raised questions such as why dual dispensation occurs in the first place and how to avoid the double dispensation of high-cost drugs. Despite the increase in quantity, May 2016 saw many high-cost items being dispensed in duplicate. These issues are inherent to process evaluation and create new opportunities for pharmacist interventions.

Regarding the limitations of the study, it is a single-center study, so the findings reflect the situation of only one PICU, which may reduce the generalizability of our findings to other clinical settings. We consider that better results could be obtained from micro-costs analysis of clinical pharmacists' performance in PICU. We could only estimate the costs of 13 of the 169 performed and accepted pharmacist interventions, which represents less than $10 \%$ of the total. The real financial impact of the interventions is much higher. Of all interventions, $84.40 \%$ of them were related to the reconstitution and dilution of medications and it was impossible to estimate the costs related to each reconstitution or dilution that did not follow the pharmacist's recommendations. Finally, these results show the limitations of a retrospective study, that is, the actions were not performed to estimate the costs involved at that time.

Other direct costs involved in patient care were not included, nor were indirect costs. Only the interventions described in the results were analyzed, without considering each patients' profile, which may decrease the external validity of the study. This study was a preliminary exploration of the impacts of pharmacist interventions on the PICU environment. A more detailed assessment of micro-costs can reveal the real impact on the institution's budget.

The results related to the individualization of antimicrobials doses can overestimate the data, because they were calculated based on the prescribed dosage for the entire period. 
Sharing vials to avoid waste is impossible, since it requires patients using the same medication at the same time.

Despite the limitations and specificities, the actions developed in this study can be applied in clinical pharmacy and preparation of injectable drugs.

\section{CONCLUSION}

This study demonstrates the implications of pharmaceutical interventions in PICU. The clinical pharmacists in pediatric intensive care units result in cost saving. Clinical pharmacist interventions, individualized antimicrobials doses, and decentralization of pharmacy services reduce costs in hospitals. We indicate strategical planning of rational medication use and management, based on local reality, which seems to provide more significant cost saving results.

\section{Authors' contributions}

BMM conception and design of the study, data collect, analysis and interpretation of data, writing the article critical, revision of the text, final approval of the article

FZL analysis and interpretation of data, critical revision of the text, final approval of the article LHL analysis and interpretation of data, critical revision of the text, final approval of the article KHS critical revision of the text, final approval of the article CRB conception and design of the study, writing the article, analysis and interpretation of data, critical revision of the text, final approval of the article

\section{REFERENCES}

Aghili M, Kasturirangan MN. A clinical pharmacist-led integrated approach for evaluation of medication errors among medical intensive care unit patients. Int J Evid-Based Healthc. 2020. In press. http://dx.doi.org/10.1097/XEB.0000000000000228. PMid:32516208.

Baldinger SL, Chow MS, Gannon RH, Kelly ET 3rd. Cost savings from having a clinical pharmacist work part-time in a medical intensive care unit. Am J Health Syst Pharm. 1997;54(24):2811-4. http://dx.doi.org/10.1093/ajhp/54.24.2811. PMid:9428951.

Brasil. Conselho Federal de Farmácia. Resolução no 675, de 31 de outubro de 2019. Regulamenta as atribuições do farmacêutico clínico em unidades de terapia intensiva, e dá outras providências. Diário Oficial da União; Brasília; 21 nov. 2019; (225):128. Seção 1.

De Giorgi I, Fonzo-Christe C, Cingria L, Caredda B, Meyer V, Pfister RE, Bonnabry P. Risk and pharmacoeconomic analyses of the injectable medication process in the paediatric and neonatal intensive care units. Int J Qual Health Care. 2010;22(3):170-8. http://dx.doi.org/10.1093/intqhc/mzq015. PMid:20382659.

Fideles GM, Alcântara-Neto JM, Peixoto Júnior AA, de Souza-Neto PJ, Tonete TL, da Silva JE, Neri ED. Pharmacist recommendations in an intensive care unit: three-year clinical activities. Rev Bras Ter Intensiva. 2015;27(2):149-54. http://dx.doi.org/10.5935/0103-507X.20150026. PMid:26340155.

Gallagher J, Byrne S, Woods N, Lynch D, McCarthy S. Cost-outcome description of clinical pharmacist interventions in a university teaching hospital. BMC Health Serv Res. 2014;14(1):177. http://dx.doi.org/10.1186/1472-6963-14-177. PMid:24742158.

Ivama A, Noblat L, Castro M, Oliveira N, Jaramillo N, Rech N. Consenso brasileiro de atenção farmacêutica: proposta. Brasília: Organização Pan-Americana da Saúde; 2002.

Kaestli LZ, Cingria L, Fonzo-Christe C, Bonnabry P. Prospective risk analysis and incident reporting for better pharmaceutical care at paediatric hospital discharge. Int J Clin Pharm. 2014;36(5):953-62. http://dx.doi.org/10.1007/s11096-014-9977-y. PMid:24997014.

Kjeldsen LJ, Jensen TB, Jensen JJ. Physicians' evaluation of clinical pharmacy revealed increased focus on quality improvement and cost savings. Dan Med Bull. 2011;58(5):A4261. PMid:21535981. 
Klopotowska JE, Kuiper R, van Kan HJ, de Pont AC, Dijkgraaf MG, Lie-A-Huen L, Vroom MB, Smorenburg SM. On-ward participation of a hospital pharmacist in a Dutch intensive care unit reduces prescribing errors and related patient harm: an intervention study. Crit Care. 2010;14(5):R174. http://dx.doi.org/10.1186/cc9278. PMid:20920322.

LaRochelle JM, Ghaly M, Creel AM. Clinical pharmacy faculty interventions in a pediatric intensive care unit: an eight-month review. J Pediatr Pharmacol Ther. 2012;17(3):263-9. http://dx.doi.org/10.5863/1551-6776-17.3.263. PMid:23258969.

Malfará M, Pernassi M, Aragon D, Carlotti A. Impact of the clinical pharmacist interventions on prevention of pharmacotherapy related problems in the paediatric intensive care unit. Int J Clin Pharm. 2018;40(3):513-9. http://dx.doi.org/10.1007/s11096-018-0632-x. PMid:29603074.

Manias E, Williams A, Liew D. Interventions to reduce medication errors in adult intensive care: a systematic review. Br J Clin Pharmacol. 2012;74(3):411-23. http://dx.doi.org/10.1111/j.13652125.2012.04220.x. PMid:22348303.

Muñoz-Pichuante D, Villa-Zapata L. Benefit of incorporating clinical pharmacists in an adult intensive care unit: a cost-saving study. J Clin Pharm Ther. 2020;45(5):1127-33. http://dx.doi.org/10.1111/jcpt.13195. PMid:32497354.

Pinto M, Santos M, Trajman A. Limiar de custo-efetividade: uma necessidade para o Brasil? J Bras Econ Saúde. 2016;8(1):58. http://dx.doi.org/10.21115/JBES.v8.n1.p58-60.

Potts AL, Barr FE, Gregory DF, Wright L, Patel NR. Computerized physician order entry and medication errors in a pediatric critical care unit. Pediatrics. 2004;113(1):59-63. http://dx.doi.org/10.1542/peds.113.1.59. PMid:14702449.

Preslaski CR, Lat I, MacLaren R, Poston J. Pharmacist contributions as members of the multidisciplinary ICU team. Chest. 2013;144(5):1687-95. http://dx.doi.org/10.1378/chest.12-1615. PMid:24189862.

Schumock GT, Butler MG, Meek PD, Vermeulen LC, Arondekar BV, Bauman JL. Evidence of the economic benefit of clinical pharmacy services: 1996-2000. Pharmacotherapy. 2003;23(1):113-32. http://dx.doi.org/10.1592/phco.23.1.113.31910. PMid:12523470.

Serafim SA, Forster AC, Simões MJ, Penaforte TR. Assessment of informatization for the dispensing of medications at a university hospital. Clinics. 2010;65(4):417-24. http://dx.doi.org/10.1590/S180759322010000400011. PMid:20454500.

Tripathi S, Crabtree HM, Fryer KR, Graner KK, Arteaga GM. Impact of clinical pharmacist on the pediatric intensive care practice: an 11-year Tertiary Center Experience. J Pediatr Pharmacol Ther. 2015;20(4):290-8. http://dx.doi.org/10.5863/1551-6776-20.4.290. PMid:26380569.

Wang T, Benedict N, Olsen KM, Luan R, Zhu X, Zhou N, Tang H, Yan Y, Peng Y, Shi L. Effect of critical care pharmacist's intervention on medication errors: a systematic review and meta-analysis of observational studies. J Crit Care. 2015;30(5):1101-6. http://dx.doi.org/10.1016/j.jcrc.2015.06.018. PMid:26260916. 